\title{
LIV. On some apparent exceptions to the law, that like crystalline forms indicate like chemical formulæ
}

James F.W. Johnston M.A. F.R.SS. L. \& E. F.G.S.

To cite this article: James F.W. Johnston M.A. F.R.SS. L. \& E. F.G.S. (1838) LIV. On some apparent exceptions to the law, that like crystalline forms indicate like chemical formulæ , Philosophical Magazine Series 3, 13:84, 405-412, DOI: 10.1080/14786443808649616

To link to this article: http://dx.doi.org/10.1080/14786443808649616

曲 Published online: 01 Jun 2009.

Submit your article to this journal $₫$

Џll Article views: 2

Q View related articles $\sqsubset$ 
the spiral is weak only, and the part even which the magnetoelectric current plays in the process of combustion is also slight. This part is, with regard to the opposed directions, at the contact, of the galvanic and of the magneto-electric current, even possibly negative. However, it may be difficult to demonstrate by direct observation the modification which connects the process of combustion, at the contact, when an electro-magnet is situated in the circle of the circuit, presupposing, that is, that the power of the galvanic current is in both cases the same, which equality must be produced by an increase in some of the electromotors corresponding to the induced opposition of conduction of the spirals.

LIV. On some apparent Exceptions to the Larw, that like Crystalline Forms indicate like Chemical Formulce. By J $\mathrm{J}_{\text {AMES }}$ F. W. Johnston, M.A., F.R.SS. L.\& E., F.G.S., \& c. \& c. Prof. Chem. and Min., University, Durham.*

FOLLOWING up the subject of a former paper on a supposed analogy in atomic constitution between the earthy carbonates and the alkaline nitrates $f$, I proceed to examine certain other cases of isomorphous coincidence between substances of which the chemical formulæ according to received views are wholly irreconcileable.

The first exception to the law that substances which replace each other may be represented by analogous formulæ was deduced by Mitscherlich from the observation that ammonia with an atom of water $\left(\mathrm{NH}_{3}+\mathrm{HO}\right)$ may replace potash (KO) in its salts, without changing their crystalline form. Six years have since elapsed and we are still without conclusive proof of any other mutual replacement of substances represented by unlike formulæ. There are indeed one or two cases in which appearances seem to render such replacement probable, but as yet no other case has been established.

We are acquainted however with a considerable number of substances, which though unlike in constitution, and incapable, or not known to be capable, of replacing each other, yet crystallize in forms which are almost or altogether identical. In the following table, extracted from my Report on Dimorphous bodies $\ddagger$, I have arranged all the cases which have hitherto come to my knowledge.

* Communicated by the Author. † See this Journal, xii. p. 480.

$\ddagger$ Report of the British Association, vol. vi. p. 175. In page 209 of the Report on Dimorphous bodies, line 5, for Isomorphism read Isomerism. 


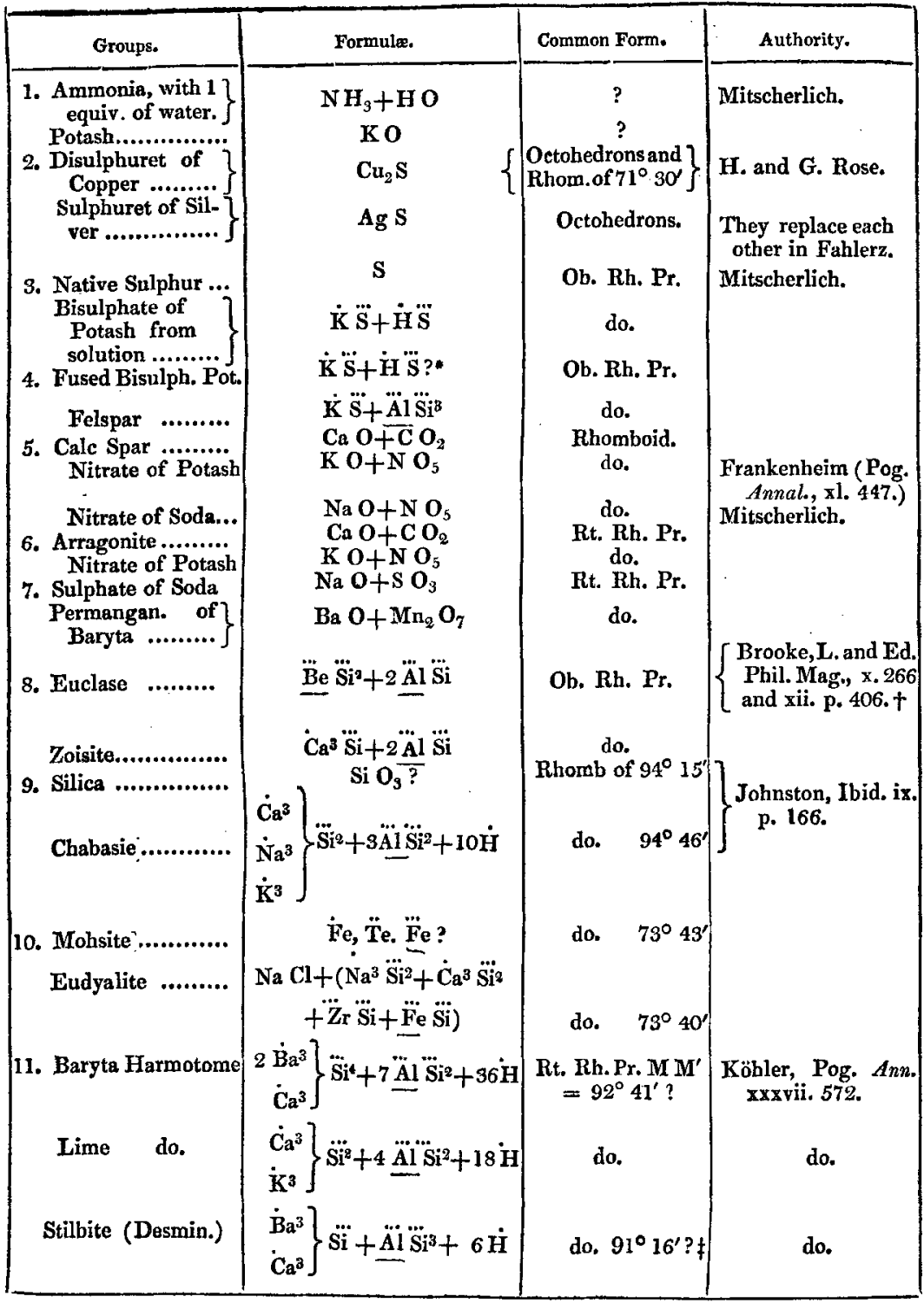

* I have marked this formula as doubtful, for though the abstract of Mitscherlich's paper in Poggendorff's Ann, xxxix, p. 196, is silent on the subject, yet Berzelius (Arsberättelse, 1837, p. 126) says that the fused crystals have a different composition. The Berlin Transactions containing Mitscherlich's entire paper have not yet reached this country.

+ The plane M on Euclase assumed by Phillips and Levy as the primary has not been observed on zoisite, but when in like position the corresponding planes on the two minerals have the same angular relations. Thus the two angles observed by Phillips in Euclase to measure 107.20 and 121.30 respectively, were found by Brooke in Zoisite to be $107^{\circ} \cdot 21$ and $121^{\circ}\left\{\begin{array}{l}30^{\prime} \\ 45^{\prime}\end{array}\right.$. Both also possess the brilliant cleavage from which Euclase derives its name.

\& Levy gives $M$ on $M$ in Harmotome and Stilbite respectively $110^{\circ} .0$ and $94^{\circ} 11^{\prime}$ The former must obviously refer to other planes than these of Köhler. 
Supposing the law to be universally true that like forms indicate like formulæ, let us inquire what changes in the received formulæ for the several members of each of the above groups it would be necessary to introduce, in order to remove the discrepancies which they exhibit.

1. If $\mathrm{KO}$ be replaced by $\mathrm{N} \mathrm{H}_{4} \mathrm{O}$, it will be necessary to suppose potassium a compound metal, and that it is truly represented by a combination $R^{\prime} R_{4}$ of two perhaps hitherto unknown elements.

2. The consequence to be deduced from the mutual replacement of the sulphurets of copper and of silver has been stated at length in a former paper *. It appears to imply that both sulphurets must be analogous in constitution, and as leading to fewer changes, that the sulphuret of silver is a disulphuret $\mathrm{Ag}_{2} \mathrm{~S}$.

This again implies that the received atom of silver must be halved, as was already suggested by its specific heat; and as a consequence, that those of gold, soda, and potash must be halved also. The facts on which this latter consequence rests are stated in the paper above referred to.

3. The next case, that native sulphur has the same form as bisulphate of potash, seems to indicate only that sulphur, so far from being a simple body, is more complicated in its constitution even than potassium, as indicated by the first group. If water may replace potash, then the formula for the bisulphate becomes $\dot{\mathrm{R}} \dddot{\mathrm{S}}$, which, to bring it into conformity with the supposed law, would require in sulphur a composition represented by $R R^{\prime}+R^{\prime \prime} R_{3}^{\prime}$.

4. If from the two formulæ in group $4^{\circ}$ we take away the atom of potash common to both, we have $2 \ddot{\mathrm{S}}+\dot{\mathrm{H}}$, and $4 \ddot{\mathrm{Si}}+\ddot{\mathrm{Al}}$ respectively. By what hypothesis these two formulæ are to be assimilated it is almost needless to inquire. Any method we could adopt would be at least as much opposed to received views as those suggested by the cases already considered.

5. Can the formulæ for nitrate of potash and calc spar be reconciled? In this Journal, vol. xii. p. 480, will be found a short paper in reply to this question. It is there shown that if the atom of potássium be halved, as our second group suggests, and if that of Berzelius for nitrogen be adopted, the formula for nitre would become $\underline{\mathbf{K}} \ddot{\mathrm{N}}$, or taking the positive elements together $\mathrm{R}_{4} \mathrm{O}_{6^{*}}$ That of calc spar is $\dot{\mathrm{Ca}} \ddot{\mathrm{C}}$, or taking * Lond. and Edinb. Phil. Mag, vol. xii. p. 324. 


\section{Prof. Johnston on apparent exceptions to the law that}

the positive elements together $\mathrm{R}_{2} \mathrm{O}_{3}$, when the ratio is the same as in nitre on the above supposition. This would imply that compounds may be isomorphous, may possibly replace each other, of which the formulæ are only so far analogous that the ratio between the positive and negative elements is the same in both. How far this is true must be determined by experiment; it at least points out a new line along which our inquiries may proceed.

6. In the sixth group the formulæ bave precisely the same relation as in the fifth.

7. In the seventh group the formula $\dot{\mathrm{Na}} \ddot{\mathrm{S}}$ has to be assimilated to Ba $\dddot{\mathrm{M}}$. This Dr. Clark proposes to do by doubling the atom of sodium, and representing the anhydrous sulphate of soda by $\ddot{\mathrm{Na}} \ddot{\mathrm{S}}$. The ratio of the positive to the negative elements in this formula is the same $(3: 8)$ as in the permanganate of baryta.

The analogy thus established between the formulæ is of the same kind as that above arrived at in regard to the members of the fifth group. It is obtained however by an inverse process by doubling instead of halving the atom of sodium. It is of importance to mark this fact, as it shows that besides the changes in received views which the reconciling of these formulæ would require, they do not all suggest like changes, and therefore any they do indicate ought to be looked upon with great suspicion. Dr. Clark has not remained satisfied with the distant analogy obtained by his method of reconciling these two formulæ. He pushes it still further, and to bring, not the whole formulæ merely, but each member of them, into exact correspondence, he represents the composition of his two salts by the more rational (?) formulæ $\mathrm{Na}: \mathrm{S}$ and $\mathrm{Ba} \dddot{\mathrm{M}} \mathrm{n}$, supposing that the whole of the oxygen enters into the composition of the acid, and that this acid thus suroxidized combines directly with the metal. It is unnecessary thus to strain isolated facts, or to attempt to remodel our entire views in regard to the salts on the faith of one solitary exception. The most important conclusion at which we shall arrive from the study of the relations among the several groups in our table will be, that from none of them can we draw any positive knowledge, though all of them afford hints which may lead to new inquiries.

8. The identity of the forms of euclase and zoisite, according to the measurements of Mr. Brooke, has given rise to 
some observations by my friend $\mathrm{Mr}$. Richard Phillips*, as if it in some way opposed the general doctrine of isomorphism.

The second member of the formulæ for these two minerals is identical, and may therefore be neglected; the first members are $\ddot{\mathrm{Be}} \mathrm{Si}^{3}$ and $\dot{\mathrm{Ca}^{s}} \ddot{\mathrm{Si}}$ respectively. If from each we take an atom of silica, then $\dddot{\mathrm{B} e} \dddot{\mathrm{S}}$ should be capable of replacing $\dot{\mathrm{C}} \mathrm{a}^{3}$; and if we suppose that glucina is not a sesqui, but a protoxide, "the supposition," according to Mr. Phillips, "most favourable to the doctrine of isomorphism ;" and that the $\ddot{\mathrm{B} e}$ of the formula should be written $\dot{\mathrm{B}}^{3}$, replacing $\dot{\mathrm{C}} \mathrm{a}^{3}$, we should still have an equivalent of silica $\ddot{\mathrm{S}} i$ in excess, in the formula for euclase. It does not appear therefore that the formulæ in the eighth group are at present to be reconciled. Were this the only case of such disagreement in formulæ, we might suspect that Mr. Brooke had mistaken one or other of the minerals, euclase or zoisite; but the number of examples which the table contains tends to remove such suspicion from the mind of those who are not so well acquainted with Mr. Brooke's accuracy and knowledge of minerals as I have had the opportunity of becoming.

9. If the forms of silica and chabasie be identical, their received formulæ appear irreconcileable.

10. Mohsite has not been analysed, but it is not easy to suppose its known constituents to be present in quantities, such as to produce a formula analogous to that of eudyalite.

11. The only relation observable among the formulæ in the 11th group is, that the second and third added together make up the first, or that the baryta harmotome may be supposed to consist of an equivalent of stilbite united to one of lime harmotome. In what way the formulæ for these two minerals are to be reconciled does not appear.

From this discussion then of the mutual relations of the formula by which the substances contained in the above groups are severally represented, we have arrived at three conclusions :

1. That some of them appear to be altogether irreconcileable.

2. That those which may be reconciled require the adoption of hypotheses which are much at variance with received opinions; and,

3. That these hypotheses may be directly the converse of each other.

- Lond. and Edin. Phil. Mag., vol. xii. p. 407. 


\section{Prof. Johnston on apparent exceptions to the law that}

If therefore we can depend on the chemical analyses and the crystalline measurements of the above substances, it is not universally true that like crystalline forms indicate like chemical formula.

Does this conclusion invalidate the general doctrine of isomorphism, or present a stumbling-block in the way of received opinions on that subject? By no means. It forms, if correct, a distinct and independent as it is an important accession to our knowledge.

To place this statement in its true light, let us consider what has been the general progress of the doctrine of isomorphism, and in what position it really stands.

1. It was observed that the sulphates, the carbonates, \&c. of entire classes of bases crystallized in forms which were specific not to each base, as magnesia and baryta, but to each class of bases, two of which were represented by magnesia and baryta as their types.

2. A similar observation was made in regard to certain salts containing different acids, as the arsenic and phosphoric; the same form being observed not merely in the arseniate and phosphate of the same base, but in such salts also of each class of bases.

3. It was therefore inferred, abstraction being made of what is common to the chemical constitution of such as have like forms, that the remainders have the same form also; that the whole class of bases, for example, lime, magnesia, \&c., had the same form, and that the class of acids, the arsenic, phosphoric, and antimonic, had also the same form, or were isomorphous.

4. This inference was confirmed by the subsequent observation that the several members of these and other classes of bases and acids might take the place of (replace) each other in quantities which might vary, but which were always proportional to their equivalents, without affecting the form of the resulting crystal.

5. But it was further observed that certain other substances appeared to replace each other, the forms of which had not been determined; that oxide of chromium, for example, might replace alumina; and hence it was inferred that such compounds must also be isomorphous; an inference which in the case of the oxide of chromium was confirmed by the examination of the crystals of this substance subsequently obtained by Wöhler.

6. Now in all these cases, substances having the same form or replacing each other, were found, or inferred to be, analogous in chemical constitution; to be oxides, sulphurets, \&c. 
which might be represented by the same general formula. It was natural, therefore, to reason in an inverse order, and to ask, if the same formula so generally follows or attends upon the same form, may not all compounds of which the form is alike be represented by like formulæ;-when put in a rational form, should not the equivalents deduced from a correct analysis give like formulæ for minerals alike in form? In this idea was presented a new and beautiful test of the accuracy of mineral analyses. Guided by it, Abieh, under the direction of Mitscherlich, examined the family of octohedral minerals, of which magnetic iron is the type, and found that spinella, gahnite, chrome, iron, \&c. may all be represented

by the same general formula $\dot{R} \ddot{R}$. Other cases of a similar kind afterwards occurred, so that it began to appear, and to be thought by many, that like forms always indicate like formulæ.

7. But then came forward one after another the anomalies or exceptions to this generalization which are grouped together in the above table, and in which the attendance of like formulæ on like forms cannot be distinguished.

By these exceptions, however, the doctrine of isomorphism is not touched, or the evidence in its favour in any way impaired. They establish, or seem to do so, merely the negative position, that like forms do not alroays in compound substances indicate like formulæ; an important and independent truth, which points to some more general law we have still to seek for, but which is perfectly consistent with the fundamental and leading principles of the isomorphic doctrine.

In the two papers published in former numbers of this Journal*, in reference to the second and fourth of the groups in the table, I was preparing the way for the consideration of the general question which has been the subject of the above remarks. The present paper I have delayed till after the publication of the 6th volume of the Reports of the British Association, that I might not anticipate my own report, of which the above table forms a part. Meanwhile my friend Mr. Richard Phillips, shocked at the changes which one of the cases I had considered seemed to indicate, hastened to publish his "Observations on Isomorphismt," some of the remarks in which, I am satisfied, he will now see to have been unnecessary. In reply to the fourth paragraph of these observations, the only one which calls for remark, I would observe, that judging from my own feelings, I am certain that

- Vol. xii. pp. 324 and $480 . \quad$ t Ibid., p. 407. 


\section{$412 \mathrm{Mr}$. Faraday's Researches in Electricity. (Series XI.)}

none of its opponents are more anxious for the discovery of truth than those whom Mr. Phillips has honoured with the title of expounders of the doctrine of isomorphism; we may have an unfortunate prejudice in favour of collecting and collating all known facts, before we venture to pronounce a decided opinion upon a difficult question, but we will not yield to them in love for the truth. We are willing to hope, however, that though we seem at present to be searching for the same truth in different directions, we may ultimately find our paths converge to one point, at which point we shall all, expounders and opponents, meet together, and at length agree *.

Durham, Sept. 12, 1838.

LV. Experimental Researches in Electricity.-Eleventh Series. By Michael. Faraday, Esq., D.C.L. F.R.S. Fullerian Prof. Chem. Royal Institution, Corr. Memb. Royal and Imp. Acadd. of Sciences, Paris, Petersburgh, Florence, Copentiagen, Berlin, \&c. \&c.

[Continued from p. 367, and concluded.]

I v. On specific Induction, or Specific inductive Capacity. 1252. NOW proceed to examine the great question of I. specific inductive capacity, i. e. whether different dielectric bodies actually do possess any influence over the degree of induction which takes place through them. If any such difference should exist, it appeared to me not only of high importance in the further comprehension of the laws and results of induction, but an additional and very powerful argument for the theory I have ventured to put forth, that the whole depends upon a molecular action, in contradistinction to one at sensible distances.

The question may be stated thus: suppose $A$ an electrified plate of metal suspended in the air, and $\mathrm{B}$ and $\mathrm{C}$ two exactly similar plates, placed parallel to and on each side of $A$ at equal distances and uninsulated; $A$ will then induce equally towards $B$ and $C$. If in this position of the plates some other dielectric than air, as shell-lac, be introduced between $\mathrm{A}$ and $\mathrm{C}$, will the induction between them remain the same? Will the relation of $\mathrm{C}$ and $\mathrm{B}$ to $\mathrm{A}$ be unaltered, notwithstanding the difference of the dielectrics interposed between them?

1253. As far as I recollect, it is assumed that no change

* If Mr. Phillips will look at the formula for chabasie given in the table, his difficulty about the mutual replacement of potash and soda will or ought to disappear. 